\title{
Development and optimization of interpenetrating network beads of Delonix regia gum and sodium alginate using response surface methodology
}

Remeth Jacky Dias, Vishwajeet Sampatrao Ghorpade, Vijay Daulatrao Havaldar, Kailas Krishnat Mali, Nitin Hindurao Salunkhe, Jyoti Harishchandra Shinde

Department of Pharmaceutics, YSPM’s Yashoda Technical Campus, Satara (415011), Maharashtra, India.

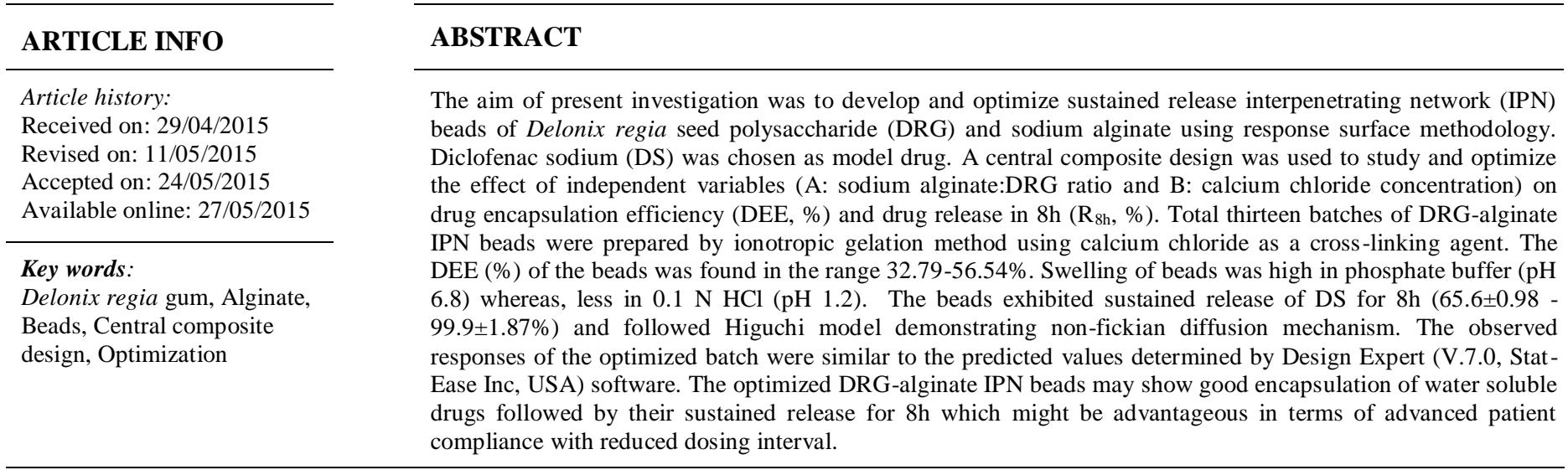

\section{INTRODUCTION}

Till date, utilization of natural polymers for the development of various sustained release drug delivery systems has been the subject of great interest because natural polymers primarily remain attractive due to their easy availability, cost effectiveness, biodegradability and biocompatibility over synthetic polymers. Importantly, chemical modifications can also be done to natural polymers (Hua et al., 2010; Satturwar et al., 2003). Literature revealed that xanthan gum, sodium alginate, cellulose ethers, scleroglucan, locust bean gum, guar gum and tamarind gum are some of the natural polysaccharides that have been evaluated in hydrophilic matrix for drug delivery systems (Salunkhe et al., 2014; Tommasina et al., 2007; Yamanaka et al., 2000). Amongst these polymers, sodium alginate has been widely used as matrix in various drug delivery applications due

\footnotetext{
* Corresponding Author

Remeth Jacky Dias, Department of Pharmaceutics, YSPM's Yashoda

Technical Campus, Satara (415011), Maharashtra, India.

Email:rjdias75@gmail.com
}

to their hydrogel forming properties (El-Kamel et al., 2003). Over the past few years, great deal of attention has been paid in the development of biopolymeric beads prepared using sodium alginate by ionotropic gelation technique (Racovita et al., 2009; Patil et al., 2010). Alginates are polysaccharides and are abundant in nature. They are found as structural components of brown marine algae (Nayak et al., 2010). Alginates undergo ionotropic gelation in presence of divalent cations (e.g., $\mathrm{Ca}^{2+}$ ) and trivalent cations (e.g., $\mathrm{Al}^{3+}$ ) where ionic cross-linking interaction occurs between the carboxylic acid groups of alginate and the respective cations. Various formulations have been developed involving successful entrapment of drugs in ionotropically cross-linked alginate hydrogels (Mali et al., 2010; Patel et al., 2006; Bogtaj et al. 2008). However, such hydrogels suffer from some serious drawbacks. It has been found that the drug entrapment efficiency of ionotropically cross-linked alginate hydrogels decreases due to leakage of drug during the long curing time (Pal and Nayak, 2011). On other hand, burst release of the drug has been observed from the pure cross-linked alginate beads (Migliaresi et al., 2014) due to faster erosion of the alginate matrix during dissolution. 
In order to overcome these problems and improve the performance of the ionotropically cross-linked alginate beads, various approaches have been used amongst which blending of different polymers is the most popular approach (Giri et al., 2013; Odeku et al., 2014). Many researchers have carried out investigations on the interpenetrating network (IPN) beads of alginate blended with other polymers including Delonix regia gum (DRG) for controlled delivery of different drugs; however a detailed study on performance of IPN hydrogel beads of DRG and sodium alginate has not been performed. Delonix regia polysaccharide, biopolymer is obtained from Delonix regia flowering plant (Gulmohar) having pod type fruits belonging to family fabaceae. Seed pods are dark brown and can be up to $60 \mathrm{~cm}$ long and $5 \mathrm{~cm}$ wide (Sandra et al., 2003; Silvana et al., 2001). The physicochemical properties of Delonix regia seed gum has been reported previously (Adetogun and Alebiowu 2009). The gum has been used as binder (Adetogun and Alebiowu 2009), release retardant in sustained release tablet dosage form (Krishnaraj et al., 2012) and for microencapsulation of bioactive natural products (Guerrero et al., 2013; Ancona et al., 2011). Diclofenac sodium (DS) is a non-steroidal anti-inflammatory drug having biological half-life of about $1-2 \mathrm{~h}$. It requires multiple dosing to maintain therapeutic drug-blood level and causes gastrointestinal disturbances, if present in large doses in gastrointestinal tract (Nayak et al., 2010; Chowdary et al., 2009). Its solubility is poor in acidic pH (Iannuccelli et al.,1993) while high in alkaline $\mathrm{pH}$ (Torres et al., 1995). The multiparticulate dosage form are advantageous over single unit preparations including more uniform dispersion in GI tract, more uniform drug absorption, reduced local irritation and elimination, and more flexible formulation process. Therefore sustained release dosage form of DS is essential, which will be able to deliver it at a slow release rate, over prolonged period. It has been a difficult task for the researchers to find out the appropriate combination of variables that will produce the product with optimum properties (Hunter, 1985). Amongst various statistical optimization designs, the central composite design which is response surface design has been commonly used for designing and optimization of different pharmaceutical formulations and process optimization (Singh et al., 2006). This technique is more flexible, very efficient and providing much information on experimental variable effects and requires minimum number of experimental runs and time. In the present investigation, the performance of IPN hydrogel beads of DRG and sodium alginate, prepared by ionotropic gelation technique, was evaluated. Taking into account above-mentioned aspects of DS, it was decided to use DS as a model drug. The prepared IPN beads were optimized by using central composite design.

\section{MATERIALS AND METHODS}

DRG was isolated and characterized in our laboratory. Sodium alginate was purchased from Loba Chemie Pvt. Ltd, Mumbai and Diclofenac sodium (DS) was received as a gift sample from Okasa Pvt. Ltd, Satara. All other chemicals and solvents used were of analytical grade.

\section{Isolation and purification of DRG}

Seeds of Delonix regia (100 g) were soaked in $800 \mathrm{ml}$ of warm water for $24 \mathrm{~h}$. The water was discarded and the seeds were immersed in $800 \mathrm{ml}$ of fresh boiling water for 4-5 h. The seeds were removed from water, washed and the tegument was broken and separated manually from the seed coat. The thick transparent cotyledon portion was separated from the seed coat and the embryonic axis. The cotyledon portion was milled and squeezed using several folds of muslin cloth to separate the marc from the filtrate. Absolute alcohol was used to precipitate the polysaccharide. The polysaccharide was separated by filtration and dried in oven at $60^{\circ} \mathrm{C}$ until constant weight. The dried polysaccharide film was milled and sifted with 80 mesh sieve and stored in desiccators (Krishnaraj et al., 2012).

\section{Preparation and Evaluation of DS loaded DRG- alginate IPN beads}

The Delonix regia gum-alginate beads containing DS were prepared by ionotropic gelation method using calcium chloride $\left(\mathrm{CaCl}_{2}\right)$ as cross-linker. Initially, aqueous solution of $3 \%$ polymer blend containing varying ratios of sodium alginate to DRG was prepared separately and mixed thoroughly with stirring for $20 \mathrm{~min}$ at $1000 \mathrm{rpm}$ using magnetic stirrer. Core material, DS (1.5\%) was dispersed in these aqueous solutions of polymer blend. The resultant aqueous dispersions were well mixed using a magnetic stirrer, at $1000 \mathrm{rpm}$ for $20 \mathrm{~min}$ and ultrasonicated for 5 min for debubbling. The final dispersion was added via an 18gauge needle drop wise into $100 \mathrm{ml}$ of $\mathrm{CaCl}_{2}$ solution. Added droplets were retained in the $\mathrm{CaCl}_{2}$ solution for 15 min to complete the curing reaction and to produce rigid beads. Microbeads were collected by filtration, washed three times with distilled water and finally dried at room temperature for overnight (Nayak et al., 2012; Nayak and Pal 2011).

\section{Experimental design for optimization}

A central composite design was employed for the optimization of Delonix regia gum-alginate IPN beads containing DS formulation. The studied factors (independent variables) were ratio of polymer blend (sodium alginate to DRG ratio) (A) and concentration of cross linking agent $\left(\mathrm{CaCl}_{2}\right)$ (B), while drug encapsulation efficiency (DEE \%) and drug release at $8 \mathrm{~h}\left(\mathrm{R}_{8 \mathrm{~h}} \%\right)$ were used as dependent variables (responses).The process variables (factors) and levels with experimental values are reported in Table 1. The matrix of the design including investigated factors and responses are shown in Table 2. Design-Expert software (V.7.0, Stat-Ease Inc, USA) was used for generation and evaluation of experimental design. Suitable polynomial equations involving individual factors and interaction factors were selected based on model analysis, correlation coefficient $\left(\mathrm{R}^{2}\right)$, adjusted correlation coefficient (adjusted $\mathrm{R}^{2}$ ), predicted correlation coefficient (predicted $\mathrm{R}^{2}$ ) and predicted residual sum of squares 
(PRESS) for the measured responses. The polynomial mathematical model generated by circumscribed central composite design is as follows:

$$
Y=b_{0}+b_{1} A+b_{2} B+b_{3} A B+b_{4} A^{2}+b_{5} B^{2}
$$

where $Y$ is the response; $b_{0}$ is the intercept, and $b_{1}, b_{2}, b_{3}, b_{4}, b_{5}$ are regression coefficients. $A$ and $B$ are individual effects; $A^{2}$ and $B^{2}$ are quadratic effects; $\mathrm{AB}$ is the interaction effect. One-way analysis of variance (ANOVA) was applied to estimate the significance of the model $(\mathrm{p}<0.05)$. The surface response plots and contour plots were analyzed to reveal the effect of independent variable (Ratio of polymer and concentration of $\mathrm{CaCl}_{2}$ ) on the measured responses (DEE and $R_{8 h}$ ).

\section{Fourier transform- infrared (FT-IR) spectroscopy}

FTIR spectra of pure DS, sodium alginate, DRG, physical mixture of drug and polymers and formulated beads were recorded using FTIR (PERKIN ELMER RX I). The powdered samples were analyzed as $\mathrm{KBr}$ pellets where the pellet was placed in the sample holder and spectral scanning was done in the wavelength region between 4000 and $400 \mathrm{~cm}^{-1}$ at a resolution of 4 $\mathrm{cm}^{-1}$ with scan speed of $1 \mathrm{~cm} / \mathrm{s}$.

\section{Differential scanning calorimetry (DSC) analysis}

DSC thermogram of pure drug, polymers, physical mixture of drug and polymers and formulated beads were recorded using Perkin Elmer instrument (PYRIS-DIAMOND TG/DTA, Osaka, Japan). Each sample (2-4 mg) was accurately weighed into $50 \mu \mathrm{l}$ aluminium pan in a hermetically sealed condition. The measurements were performed in an atmosphere of nitrogen (150 $\mathrm{ml} / \mathrm{min}$ ) between $32^{\circ} \mathrm{C}$ and $250^{\circ} \mathrm{C}$ at a heating rate of $15^{\circ} \mathrm{C} / \mathrm{min}$. Platinum crucible with alpha alumina powder was used as reference.

\section{Scanning electron microscopy (SEM)}

Scanning electron microscopy (JSM-5800; JEOL Ltd., Tokyo, Japan) was used to evaluate the shape and surface topography of the microbeads. Beads were gold coated by mounted on a brass stub using double-sided adhesive tape and under vacuum in an ion sputter with a thin layer of gold $(3-5 \mathrm{~nm})$ for $75 \mathrm{~s}$ and at $15 \mathrm{kV}$ to make them electrically conductive and their morphology was examined.

\section{Determination of drug encapsulation efficiency (DEE)}

Accurately weighed, $100 \mathrm{mg}$ of beads were taken from all batches and crushed using mortar and pestle. The crushed powder of beads containing drug were placed in $500 \mathrm{ml}$ of phosphate buffer ( $\mathrm{pH}$ 6.8), and kept it for $24 \mathrm{~h}$ with occasional shaking at $37 \pm 0.5^{\circ} \mathrm{C}$. After that, the mixture was stirred at 500 rpm for 20 min using magnetic stirrer. The polymer debris formed after the disintegration of beads was removed by filtering through Whatman filter paper (No. 40). The filtrate was analyzed spectrophotometrically at $276 \mathrm{~nm}$ (Shimadzu 1800, Japan) (Nayak and Pal 2011; Bhattacharya et al., 2012). The DEE of beads was calculated using the formula;

$$
\operatorname{DEE}(\%)=\frac{\text { Actual Drug Content }}{\text { Theoretical Drug Content }} \times 100
$$

\section{Swelling index}

Swelling behavior of DS loaded DRG-alginate IPN beads from all batches were studied in two different aqueous media, 0.1 $\mathrm{N} \mathrm{HCl}$ (pH 1.2) and phosphate buffer ( $\mathrm{pH}$ 6.8). Beads (100 mg) were placed in vessel of dissolution apparatus containing $500 \mathrm{ml}$ respective media. The experiment was carried out at $37 \pm 1^{\circ} \mathrm{C}$ under $50 \mathrm{rpm}$ paddle speed. The swollen beads were removed at predetermined time intervals and weighed after drying the surface by using tissue paper (Nayak and Pal 2011; Bhattacharya et al., 2012).

Swelling Index $(\%)=$

$\frac{\text { Weight of beads after swelling-Dry weight of beads }}{\text { Dry weight of beads }} \times 100$

\section{In vitro drug release}

In vitro drug release studies were performed for microbeads of all batches in USP dissolution apparatus II (TDT08L, Electrolab, India) using $900 \mathrm{ml}$ of $0.1 \mathrm{~N} \mathrm{HCl}$ for $2 \mathrm{~h}$ and phosphate buffer pH 6.8 for remaining 6 h. Rotation speed was controlled at $50 \mathrm{rpm}$ while temperature was maintained at $37 \pm$ $0.5^{\circ} \mathrm{C}$. At the end of $2 \mathrm{~h}, 0.1 \mathrm{~N} \mathrm{HCl}$ was replaced with phosphate buffer $\mathrm{pH} 6.8$ and the study was continued for next $6 \mathrm{~h}$. At regular time intervals, an aliquot was removed and replenished with fresh pre warmed medium. The aliquot was assayed for DS content using a UV spectrophotometer (UV-1800, Shimadzu, Japan) at $276 \mathrm{~nm}$.

\section{Analysis of in vitro drug release kinetics and mechanism}

In order to predict and correlate the in vitro drug release behavior from beads, it is necessary to fit into suitable mathematical model. The in vitro drug release data were evaluated kinetically using various important mathematical models like Zero order, First order, Hixon crowell, Higuchi and Korsmeyer-Peppas models.

\section{Statistical analysis}

All measured data are expressed as mean \pm standard deviation (S.D). Each measurement was done in triplicate.

\section{RESULTS AND DISCUSSION}

\section{Isolation of DRG and preparation of Delonix regia gum- alginate beads containing DS}

DRG was isolated from Delonix regia seeds, and the average yield of dried DRG was found to be $74.8 \%$. DS loaded DRG-alginate IPN beads were prepared by ionotropic gelation technique using $\mathrm{CaCl}_{2}$ solution as a cross-linker. When dispersion mixture of sodium alginate, DRG and DS was dropped into the solutions containing calcium ions, gelled spherical DRG-alginate IPN beads containing DS were formed instantaneously due to electrostatic interaction between negatively charged sodium alginate and positively charged calcium ion. 
Table 1: Factors and levels of the central composite design used for optimization.

\begin{tabular}{|c|c|c|}
\hline \multirow{2}{*}{ Normalized levels } & \multicolumn{2}{|c|}{ Independent variables (factors) } \\
\hline & SA:DRG ${ }^{\mathrm{a}}(\mathrm{A})$ & $\mathrm{CaCl}_{2}(\%$ w/v $)(\mathrm{B})$ \\
\hline-1.414 & 1.59 & 2.93 \\
\hline-1 & 2.00 & 5.00 \\
\hline 0 & 3.00 & 10.00 \\
\hline 1 & 4.00 & 15.00 \\
\hline 1.414 & 4.41 & 17.07 \\
\hline
\end{tabular}

*SA: sodium alginate; DRG: Delonix regia gum

Table 2: Experimental plan and observed response values from randomized run in central composite design

\begin{tabular}{|c|c|c|c|c|}
\hline \multirow{2}{*}{$\begin{array}{c}\text { Experimental } \\
\text { Runs }\end{array}$} & \multicolumn{2}{|c|}{ Normalized levels of factors } & \multicolumn{2}{|c|}{ Responses } \\
\hline & SA: DRG (A) & $\mathrm{CaCl}_{2}(\% \mathrm{w} / \mathrm{v})(\mathrm{B})$ & DEE (\%) & $\left(\mathbf{R}_{8} \mathrm{~h} \%\right)$ \\
\hline R-1 & 2.00 & 15.00 & $48.47 \pm 1.53$ & $72.4 \pm 2.81$ \\
\hline $\mathrm{R}-2$ & 3.00 & 2.93 & $44.77 \pm 1.75$ & $98 \pm 0.97$ \\
\hline $\mathrm{R}-3$ & 3.00 & 17.07 & $35.96 \pm 2.24$ & $82.8 \pm 2.29$ \\
\hline $\mathrm{R}-4$ & 1.59 & 10.00 & $56.54 \pm 0.22$ & $65.6 \pm 0.98$ \\
\hline $\mathrm{R}-5$ & 3.00 & 10.00 & $54.26 \pm 1.47$ & $93.7 \pm 0.96$ \\
\hline R-6 & 4.00 & 15.00 & $33.83 \pm 0.66$ & $98.6 \pm 1.64$ \\
\hline $\mathrm{R}-7$ & 4.41 & 10.00 & $48.01 \pm 0.92$ & $99.3 \pm 1.33$ \\
\hline $\mathrm{R}-8$ & 3.00 & 10.00 & $53.53 \pm 1.60$ & $90.7 \pm 2.75$ \\
\hline R-9 & 3.00 & 10.00 & $53.42 \pm 1.68$ & $94.2 \pm 2.55$ \\
\hline $\mathrm{R}-10$ & 4.00 & 5.00 & $32.79 \pm 0.88$ & $99.9 \pm 1.87$ \\
\hline $\mathrm{R}-11$ & 3.00 & 10.00 & $53.83 \pm 0.97$ & $91.7 \pm 2.40$ \\
\hline R-12 & 2.00 & 5.00 & $38.13 \pm 1.24$ & $99.2 \pm 2.61$ \\
\hline $\mathrm{R}-13$ & 3.00 & 10.00 & $53.38 \pm 1.65$ & $93.4 \pm 1.06$ \\
\hline
\end{tabular}

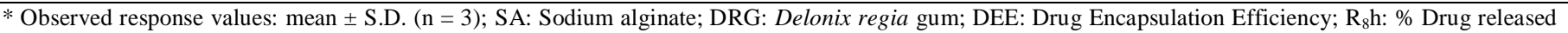
from DRG-alginate beads containing diclofenac sodium in $8 \mathrm{~h}$.

Table 3: Model summary statistics for measured responses in central composite design.

\begin{tabular}{|c|c|c|c|c|c|c|c|c|}
\hline & \multicolumn{4}{|c|}{ DEE $(\%)$} & \multicolumn{4}{|c|}{$\mathrm{R}_{8 \mathrm{~h}}(\%)$} \\
\hline & $\mathbf{R}^{2}$ & Adjusted R ${ }^{2}$ & Predicted $\mathbf{R}^{2}$ & PRESS $^{\mathbf{a}}$ & $\mathbf{R}^{2}$ & Adjusted R ${ }^{2}$ & Predicted $\mathbf{R}^{2}$ & PRESS $^{\mathbf{a}}$ \\
\hline Linear & 0.1425 & -0.029 & -0.609 & 1450.9 & 0.7138 & 0.6566 & 0.389 & 857.991 \\
\hline $2 \mathrm{FI}^{\mathrm{b}}$ & 0.1664 & -0.111 & -1.762 & 2491.2 & 0.8296 & 0.7728 & 0.5448 & 639.257 \\
\hline Quadratic & 0.7695 & 0.6049 & -0.636 & 1475.3 & 0.9009 & 0.8301 & 0.3167 & 959.548 \\
\hline Cubic & 0.857 & 0.6567 & -8.118 & 8223.6 & 0.9431 & 0.8635 & -2.398 & 4771.4 \\
\hline
\end{tabular}

DEE (\%), drug encapsulation efficiency (\%); $\mathrm{R}_{8 \mathrm{~h}}(\%)$, \% drug released from DRG-alginate beads in $8 \mathrm{~h}$.

${ }^{\mathrm{a}}$ PRESS, predicted residual sum of squares.

b 2 FI, two factor interaction.

Table 4: Summary of ANOVA for the response parameters.

\begin{tabular}{|c|c|c|c|c|c|}
\hline Source & Sum of square & d.f $^{d}$ & Mean square & F-value & P-value Prob $>$ F \\
\hline \multicolumn{6}{|c|}{ For DEE (\%) } \\
\hline Model & 694.05 & 5 & 138.81 & 4.6744 & 0.0339 \\
\hline A & 128.35 & 1 & 128.35 & 4.322 & 0.0762 \\
\hline $\mathrm{B}$ & 0.1456 & 1 & 0.1456 & 0.0049 & 0.9461 \\
\hline $\mathrm{AB}$ & 21.623 & 1 & 21.623 & 0.7281 & 0.4217 \\
\hline $\mathrm{A}^{2}$ & 52.16 & 1 & 52.16 & 1.7565 & 0.2267 \\
\hline $\mathrm{B}^{2}$ & 525.72 & 1 & 525.72 & 17.703 & 0.004 \\
\hline \multicolumn{6}{|c|}{ For $\mathrm{R}_{8 \mathrm{~h}}(\%)$} \\
\hline Model & 1164.9 & 3 & 388.3 & 14.602 & 0.0008 \\
\hline A & 694.88 & 1 & 694.88 & 26.13 & 0.0006 \\
\hline B & 307.47 & 1 & 307.47 & 11.562 & 0.0079 \\
\hline $\mathrm{AB}$ & 162.56 & 1 & 162.56 & 6.113 & 0.0354 \\
\hline
\end{tabular}

*A and $\mathrm{B}$ are individual effects; $\mathrm{A}^{2}$ and $\mathrm{B}^{2}$ are quadratic effects; $\mathrm{AB}$ is the interaction effect; d.f.: degree of freedom; DEE: Drug Encapsulation Efficiency in \%; $\mathrm{R}_{8} \mathrm{~h}$ : \% Drug released from DRG-alginate beads containing diclofenac sodium in $8 \mathrm{~h}$.

Table 5: Swelling behavior of DS loaded DRG-alginate composite beads in $0.1 \mathrm{~N} \mathrm{HCl}(\mathrm{pH} 1.2)$ and phosphate buffer (pH 6.8)

\begin{tabular}{|c|c|c|c|c|c|c|c|c|c|c|c|c|c|}
\hline \multirow{2}{*}{$\begin{array}{l}\text { Time } \\
\text { (h) }\end{array}$} & \multicolumn{13}{|c|}{ Swelling Ratio (\%) ${ }^{\mathrm{a}}$} \\
\hline & R-1 & R-2 & R-3 & R-4 & R-5 & R-6 & R-7 & R-8 & R-9 & R-10 & R-11 & R-12 & R-13 \\
\hline $1^{*}$ & $150 \pm 1.23$ & $99 \pm 3.16$ & $50 \pm 1.52$ & $99 \pm 1.50$ & $62 \pm 2.32$ & $172 \pm 1.24$ & $31 \pm 2.25$ & $236 \pm 2.08$ & $320 \pm 1.82$ & $275 \pm 2.12$ & $113 \pm 3.25$ & $301 \pm 1.23$ & $363 \pm 3.04$ \\
\hline $2 *$ & $296 \pm 2.51$ & $399 \pm 2.54$ & $322 \pm 1.64$ & $316 \pm 1.02$ & $262 \pm 2.19$ & $400 \pm 3.45$ & $151 \pm 3.35$ & $358 \pm 2.14$ & $421 \pm 1.36$ & $307 \pm 3.05$ & $289 \pm 2.19$ & $337 \pm 1.95$ & $333 \pm 1.83$ \\
\hline $3 * *$ & $569 \pm 3.42$ & $720 \pm 3.87$ & $575 \pm 1.89$ & $770 \pm 2.87$ & $642 \pm 3.05$ & $483 \pm 2.26$ & $313 \pm 1.45$ & $608 \pm 3.36$ & $760 \pm 1.15$ & $696 \pm 3.14$ & $620 \pm 2.56$ & $782 \pm 2.11$ & $610 \pm 1.45$ \\
\hline $4 * *$ & $871 \pm 1.22$ & $876 \pm 1.08$ & $864 \pm 2.08$ & $891 \pm 2.46$ & $882 \pm 1.41$ & $873 \pm 2.34$ & $710 \pm 0.64$ & $883 \pm 1.29$ & $883 \pm 2.19$ & $874 \pm 2.68$ & $882 \pm 1.44$ & $894 \pm 2.38$ & $882 \pm 2.10$ \\
\hline $5^{* *}$ & $613 \pm 1.98$ & $870 \pm 1.64$ & $538 \pm 3.13$ & $756 \pm 2.06$ & $631 \pm 1.67$ & $774 \pm 1.45$ & $206 \pm 2.15$ & $706 \pm 1.56$ & $810 \pm 2.36$ & $840 \pm 1.78$ & $519 \pm 1.32$ & $810 \pm 2.06$ & $822 \pm 2.76$ \\
\hline $6^{* *}$ & $131 \pm 2.35$ & $522 \pm 1.53$ & $252 \pm 1.23$ & $430 \pm 1.87$ & $262 \pm 1.52$ & $285 \pm 1.09$ & $180 \pm 1.78$ & $620 \pm 3.12$ & $612 \pm 1.24$ & $457 \pm 1.84$ & $271 \pm 1.05$ & $669 \pm 2.08$ & $648 \pm 0.56$ \\
\hline $7 * *$ & $108 \pm 3.24$ & $102 \pm 2.21$ & $135 \pm 1.45$ & $142 \pm 1.45$ & $54 \pm 2.30$ & $186 \pm 1.35$ & $18 \pm 1.45$ & $278 \pm 2.55$ & $290 \pm 1.02$ & $225 \pm 1.36$ & $111 \pm 1.68$ & $262 \pm 1.50$ & $188 \pm 1.35$ \\
\hline $8^{* *}$ & $98 \pm 1.86$ & $42 \pm 2.57$ & $115 \pm 2.20$ & $132 \pm 1.63$ & $34 \pm 1.87$ & $106 \pm 2.05$ & $16 \pm 3.12$ & $248 \pm 1.32$ & $270 \pm 1.16$ & $195 \pm 0.84$ & $91 \pm 1.87$ & $212 \pm 1.06$ & $68 \pm 1.47$ \\
\hline
\end{tabular}

${ }^{\mathrm{a}}$ Mean $\pm \mathrm{SD}, \mathrm{n}=3$

* Study in $0.1 \mathrm{~N} \mathrm{HCl}(\mathrm{pH} 1.2)$

** Study in phosphate buffer $(\mathrm{pH} 6.8)$ 
Table 6: Results of curve fitting of the in vitro diclofenac release data from different delonix regia gum- alginate beads.

\begin{tabular}{cllllll}
\hline Experimental & \multicolumn{2}{l}{ Correlation coefficient $\left(\mathbf{r}^{2}\right)$} & & & \multicolumn{2}{c}{$\begin{array}{l}\text { Release } \\
\text { Exponent }(\mathbf{n})\end{array}$} \\
\cline { 2 - 6 } Runs & Zero order & First order & Korsmeyer Peppas & Higuchi & Hixon-crowell & 0.539 \\
R-1 & 0.999 & 0.974 & 0.983 & 0.975 & 0.972 & 0.585 \\
R-2 & 0.981 & 0.938 & 0.980 & 0.982 & 0.830 & 0.726 \\
R-3 & 0.929 & 0.806 & 0.970 & 0.981 & 0.993 & 0.656 \\
R-4 & 0.991 & 0.912 & 0.997 & 0.995 & 0.994 & 0.832 \\
R-5 & 0.962 & 0.842 & 0.986 & 0.994 & 0.981 & 0.780 \\
R-6 & 0.937 & 0.814 & 0.975 & 0.975 & 0.899 & 0.699 \\
R-7 & 0.918 & 0.783 & 0.965 & 0.967 & 0.899 & 0.814 \\
R-8 & 0.964 & 0.829 & 0.984 & 0.997 & 0.993 & 0.825 \\
R-9 & 0.927 & 0.750 & 0.947 & 0.985 & 0.984 & 0.631 \\
R-10 & 0.739 & 0.654 & 0.879 & 0.850 & 0.923 & 0.811 \\
R-11 & 0.970 & 0.858 & 0.990 & 0.997 & 0.991 & 0.634 \\
R-12 & 0.820 & 0.738 & 0.990 & 0.906 & 0.991 & 0.909 \\
R-13 & 0.975 & 0.858 & 0.991 & 0.999 & 0.966 & \\
\hline
\end{tabular}

Table 7: Results of experiments for confirming optimization capability.

\begin{tabular}{|c|c|c|c|c|c|c|c|c|}
\hline Code & \multicolumn{2}{|c|}{ Factors } & \multicolumn{6}{|c|}{ Responses } \\
\hline $\mathrm{R}-\mathrm{O}$ & 3 & 8.62 & 53.11 & $51.74 \pm 1.54$ & 2.58 & 92.52 & $89.68 \pm 2.52$ & 3.08 \\
\hline
\end{tabular}

SA:DRG, sodium alginate-to-Delonix regia gum ratio; DEE: Drug Encapsulation Efficiency; $\mathrm{R}_{8} \mathrm{~h}$ : \% Drug released from DRG-alginate beads containing diclofenac sodium in $8 \mathrm{~h}$.

${ }^{a}$ Observed response values; mean $\pm \mathrm{SD}(\mathrm{n}=3)$

${ }^{\mathrm{b}}$ Error $(\%)=[$ Difference between predicted value and observed value/Predicted value $] \times 100$
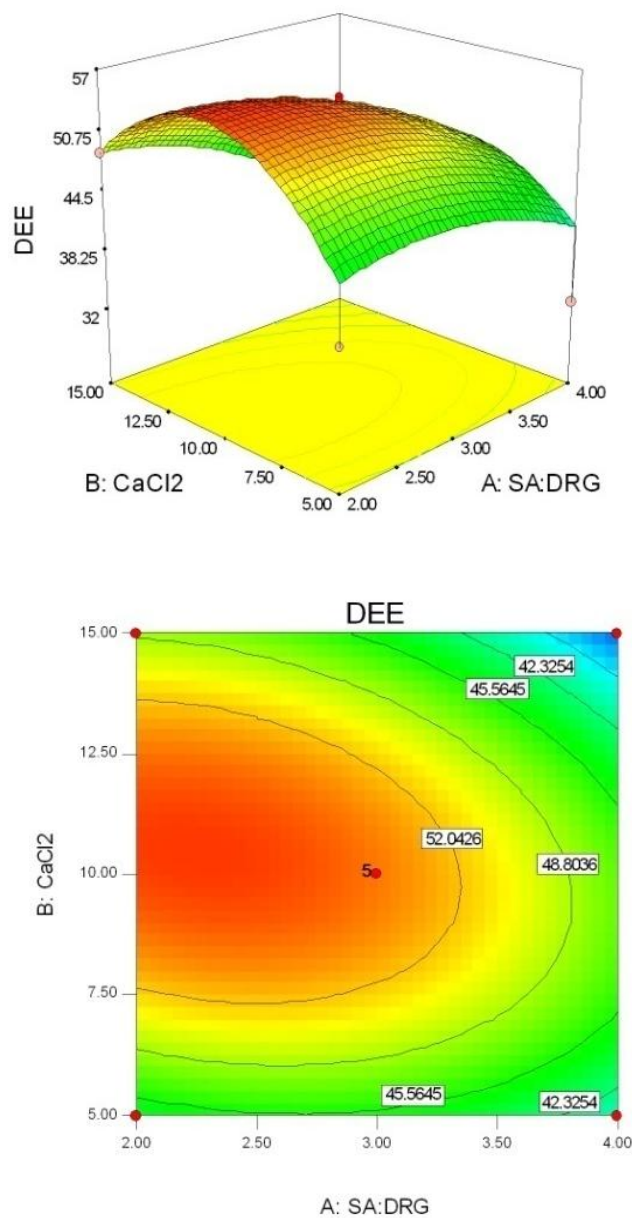
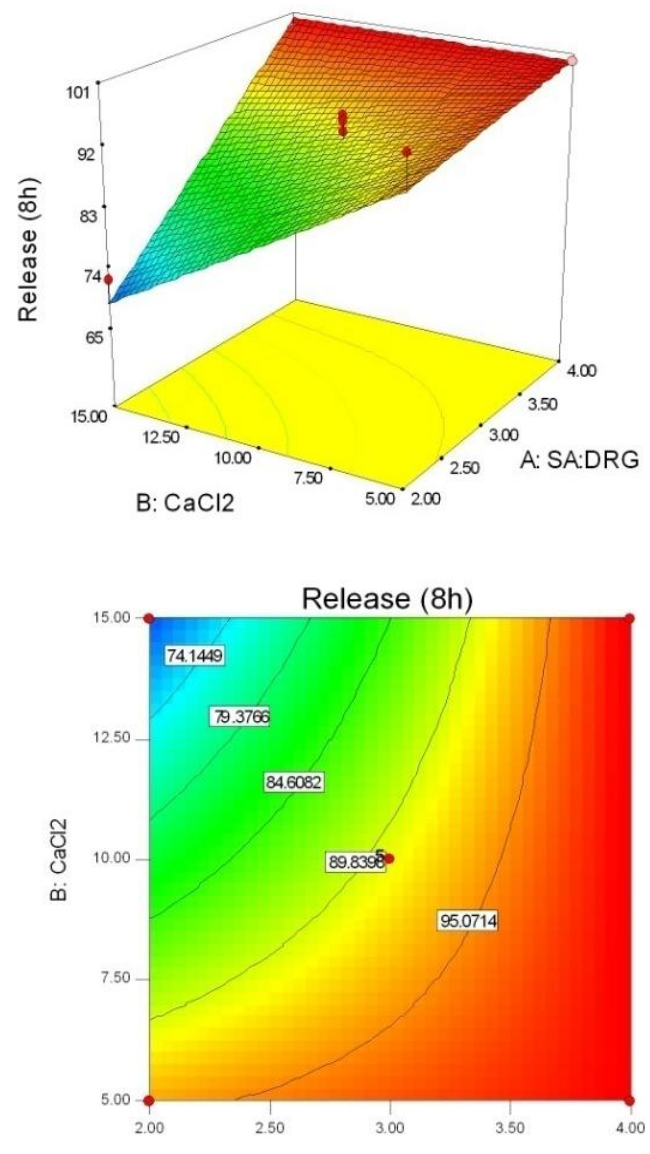

A: SA:DRG

Fig. 1: Three dimensional response surface plots (a and b) and contour plots (c and d) showing the effect of amount of sodium alginate (mg) and Delonix regia gum (mg) on DEE (\%) and $\mathrm{R}_{8 \mathrm{~h}}(\%)$. 


\section{Optimization by central composite design}

In conventional optimization process by changing one factor at a time, the optimization is usually carried out by varying a single factor and keeping all other factors fixed at specific set of conditions, this method is time consuming and incapable of effective optimization as it does not consider the interactive effects of all the primary factors. It is therefore important to understand the influence of formulation variables to develop optimized formulation using established statistical tools such as central composite design. Central composite design is a response surface design, which provides information on individual effects, pairwise interaction of various individual effects and curvilinear variables effects. In the current investigation, a central composite design with total 13 experimental formulations of DRG-alginate beads containing DS were proposed by Design- Expert (V.7.0, Stat-Ease Inc, USA) software for two independent process variables (factors): amount of $\mathrm{SA}$ : $\mathrm{DRG}(\mathrm{A})$ and $\mathrm{CaCl}_{2}$ concentration(B). The effects of these independent variables on DEE (Y1) and $R_{8 h}$ (Y2) were investigated. Overview of experimental plan and observed response values are presented in Table 2. A quadratic model and a two factor interaction model (2FI) were selected as suitable statistical model for optimization of DEE (\%) and $\mathrm{R}_{8 \mathrm{~h}}(\%)$ respectively, based on maximum Adjusted $\mathrm{R}^{2}$ and low PRESS value (see Table 3 ). The model was evaluated statistically by applying one way ANOVA ( $<<0.05)$, which is shown in Table 4. The model $\mathrm{p}$ values of less than 0.05 for both the measured responses implied the models were significant $(\mathrm{p}<$ $0.05)$.

The model equation relating $\mathrm{DEE}(\%)$ as response is shown in Eq. 4:

$\mathrm{Y}_{1}=53.74-4.01 \mathrm{~A}-0.13 \mathrm{~B}-2.32 \mathrm{AB}-2.74 \mathrm{~A}^{2}-8.69 \mathrm{~B}^{2}\left(\mathrm{R}^{2}=0.7695\right.$, $\mathrm{p}<0.0339) \ldots(4)$

The model equation relating $\mathrm{R}_{8 \mathrm{~h}}(\%)$ as response is shown in Eq. 5: $\mathrm{Y}_{2}=90.81+9.32 \mathrm{~A}-6.20 \mathrm{~B}+6.38 \mathrm{AB}\left(\mathrm{R}^{2}=0.8296, \mathrm{p}<\right.$ $0.0008) \ldots(5)$

Design - Expert V.7.0 software generated three-dimensional response surface plots and corresponding contour plots relating investigated responses, $\operatorname{DEE}(\%)$ and $\mathrm{R}_{8 \mathrm{~h}}(\%)$. The three dimensional response surface plot is useful to study about the main and interaction effects of independent variables (Factors), where as two dimensional contour plot gives a visual representation of values of the response. The three dimensional response surface plots relating DEE (\%) and $\mathrm{R}_{8 \mathrm{~h}}$ are presented in Figure 1(a) and Figure 1(b). The two dimensional corresponding contour plots relating DEE $(\%)$ and $\mathrm{R}_{8 \mathrm{~h}}$ are presented in Figure 1 (c) and Figure $1(\mathrm{~d})$. The respective plots relating DEE $(\%)$ and $\mathrm{R}_{8 \mathrm{~h}}(\%)$ depends on the ratio of polymer concentration and concentration of $\mathrm{CaCl}_{2}$ $(\%)$.

Further, the DS loaded DRG-alginate IPN beads were optimized for both the responses, $\mathrm{Y}_{1}$ (DEE in \%) and $\mathrm{Y}_{2}\left(\mathrm{R}_{8 \mathrm{~h}}\right.$ in $\%)$. The desirable ranges of factors were restricted to $2 \leq \mathrm{SA}$ :DRG $\leq 3$ and $7.5 \leq \mathrm{CaCl}_{2} \leq 12.5$; whereas ranges of responses were restricted to $32.79 \leq \mathrm{Y}_{1} \leq 56.54$ and $65.6 \leq \mathrm{Y}_{2} \leq 99.9$. The optimal values of responses were obtained by numerical analysis using the
Design Expert software (V.7.0, Stat-Ease Inc, USA) based on criterion of desirability. In order to evaluate the optimization capability of the models generated according to the results of central composite design, DS loaded DRG-alginate IPN beads were prepared using optimal process variable settings. The optimized formulations of DS loaded DRG-alginate IPN beads (RO) were evaluated for $\operatorname{DEE}(\%)$ and $\mathrm{R}_{8 \mathrm{~h}}(\%)$. The results of experiments with predicted responses by mathematical model and those observed are shown in Table 7.

The optimized DRG-alginate IPN beads showed maximum DEE $(51.74 \pm 1.54 \%)$ and maximum $\mathrm{R}_{8 \mathrm{~h}}(89.68 \pm 2.52 \%)$ with small error values (2.58 and 3.08, respectively). This reveals that mathematical designs obtained by central composite designs were well fitted.

\section{Fourier transform- infrared (FT-IR) spectroscopy}

FTIR spectra of DS, DRG, Sodium alginate, physical mixture and DS loaded DRG-alginate beads are shown in Figure 2. FTIR spectrum of DS (Figure 2A) showed characteristic peaks at 3259, 2972, 1573, 1556, 1396 and $744 \mathrm{~cm}^{-1}$, indicating the stretching of $\mathrm{N}-\mathrm{H}, \mathrm{C}-\mathrm{H}$, aromatic $\mathrm{C}=\mathrm{C}, \mathrm{C}=\mathrm{O}$ (asymmetric), $\mathrm{C}=\mathrm{O}$ (symmetric) and aromatic $\mathrm{C}-\mathrm{Cl}$ respectively.

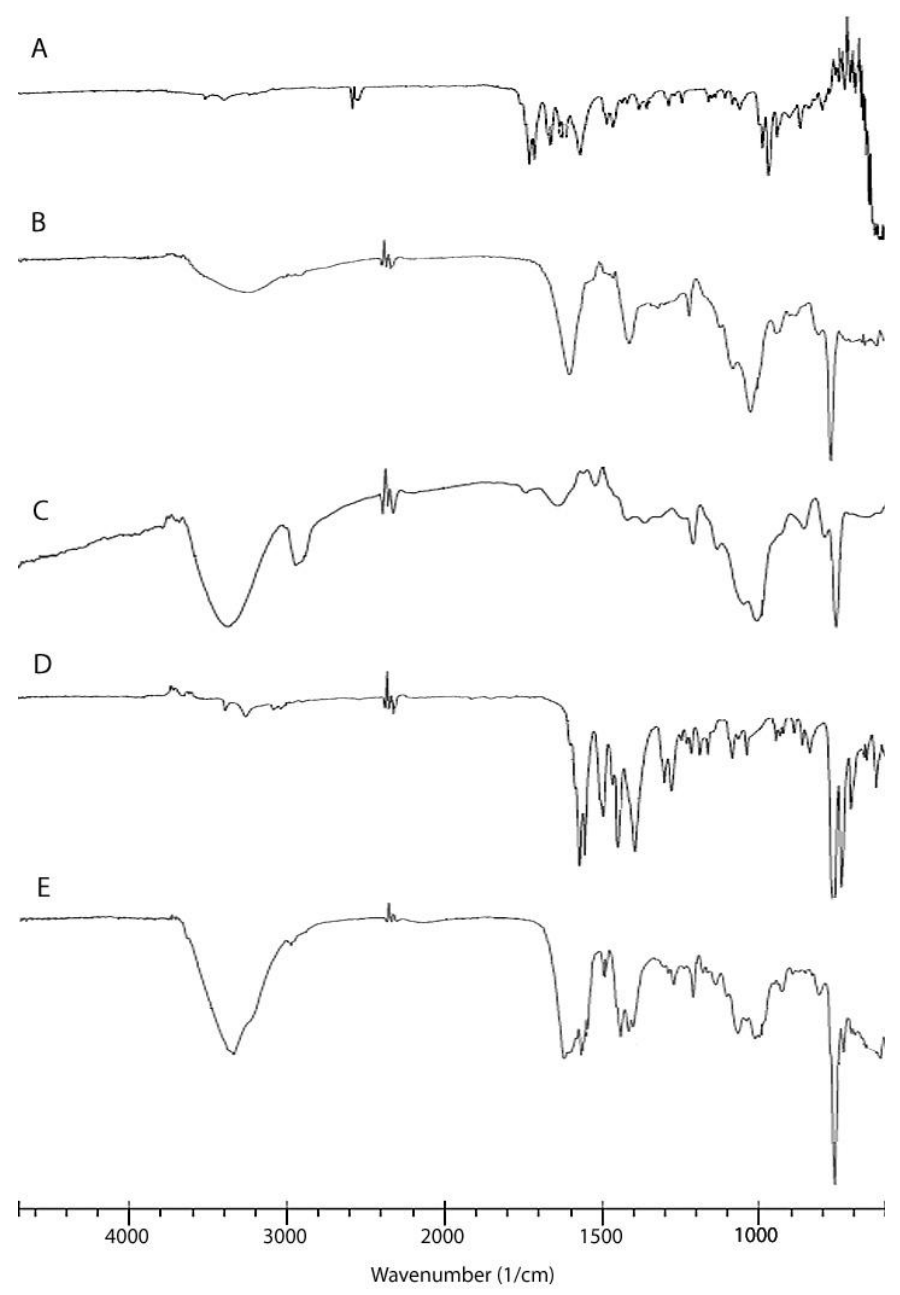

Fig. 2: FTIR spectra of DS (A), DRG (B), Sodium alginate (C), Physical mixture of formulation (D), DS loaded DRG-alginate IPN beads (E) 
The characteristic peaks of DS were observed in the spectra of physical mixture and DS loaded DRG-alginate beads with negligible shifts due to peaks of sodium alginate and DRG lying in the same region. The noticeable shifts or disappearance of peaks were not observed which showed lack of drug-polymer or polymer-polymer interactions.

\section{Differential scanning calorimetry}

The DSC thermogram of DS, DRG, sodium alginate, physical mixture and formulation are shown in Figure 3. The DSC thermogram of DS showed peak at $290^{\circ} \mathrm{C}$ which is the melting point of the drug. The DSC thermogram of physical mixture and formulation showed no peaks at $290^{\circ} \mathrm{C}$ indicating uniform dispersion of DS at molecular level in the beads.

A

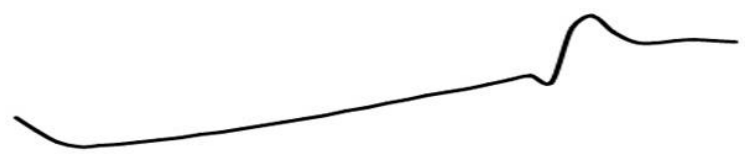

B
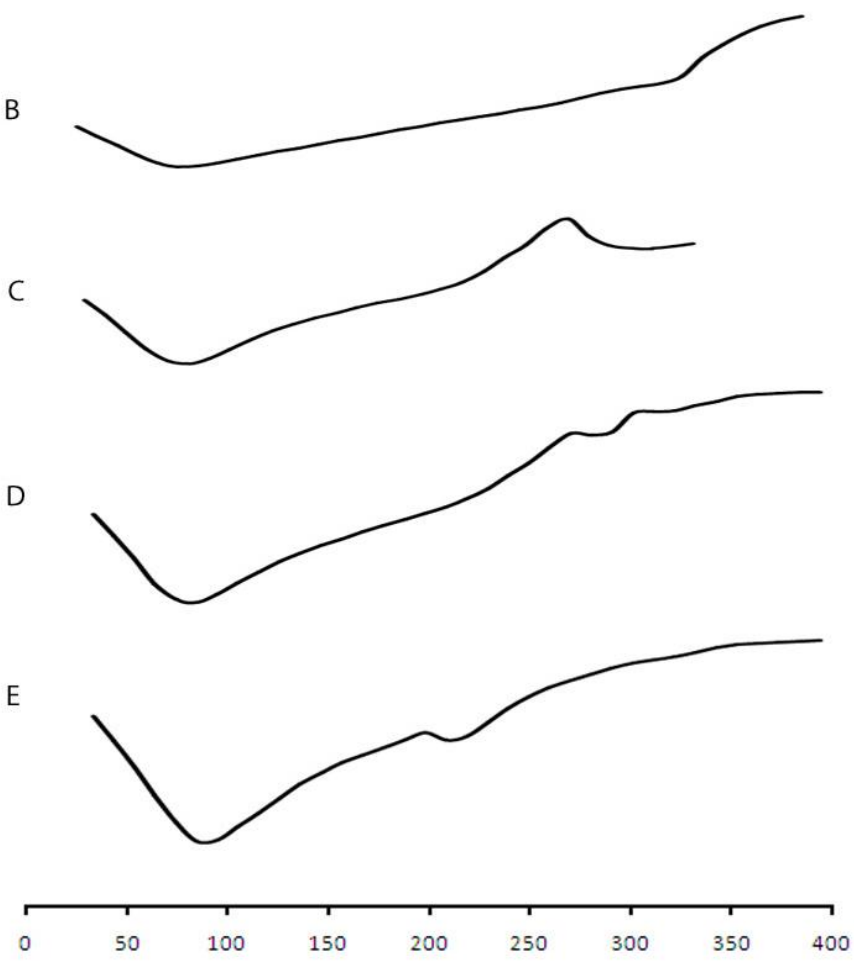

Temperature $\left({ }^{\circ} \mathrm{C}\right)$

Fig. 3: DSC pattern of DS (A), DRG (B), Sodium alginate (C), Physical mixture of formulation (D), DS loaded DRG-alginate IPN beads (E)

\section{Scanning electron microscopy}

The morphological analysis of DRG-alginate IPN beads containing DS was visualized by SEM at different magnifications and is presented in Figure 4. The SEM photograph of these beads showed spherical shape with a rough surface. Detailed examination of the bead surface topography revealed cracks and wrinkles, which might be caused by partial collapsing of the polymeric gel network during drying.

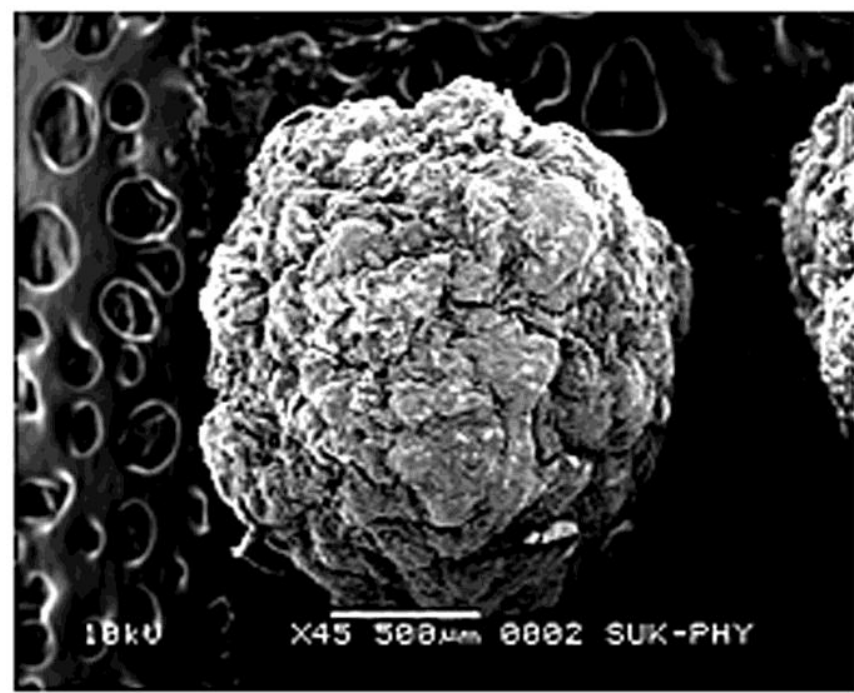

Fig. 4: Scanning electron microphotograph of optimized beads

\section{Drug encapsulation efficiency}

The DEE of DRG-alginate IPN beads containing DS was found within the range of $32.79-56.54 \%$ respectively shown in Table 2. The increased DEE with decreasing sodium alginate to DRG ratio may be due to the increase in viscosity of the gel membrane by the addition of DRG as polymeric blend with sodium alginate, so that, it might have prevented drug squeezing out to the external solution during curing. DEE was found to be increased with increase in concentration of cross linking agent upto $10 \%$. This may be due to increase in the degree of crosslinking which might have reduced the leaching of drug in the cross-linking solution. Further on increasing conc. of $\mathrm{CaCl}_{2}, \mathrm{DEE}$ was found to be decreased which may be attributed to insufficient cross-linking and large pore size permitting the drug to diffuse out during gelation which leads to lower drug encapsulation efficiency. Similar observations have been reported by Das et al., 2007.

\section{Swelling behavior}

The swelling behaviors of DS loaded DRG-alginate IPN beads were evaluated in $0.1 \mathrm{~N} \mathrm{HCl}$ and phosphate buffer, $\mathrm{pH} 6.8$ as shown in Table 5. Initially swelling index of DRG-alginate IPN beads was lower in $0.1 \mathrm{~N} \mathrm{HCl}$ in comparison with phosphate buffer. This may be due to shrinkage of alginate at acidic $\mathrm{pH}$. The beads exhibited maximum swelling at 4-5 $\mathrm{h}$ in alkaline $\mathrm{pH}$ followed by erosion and dissolution. The swelling behavior of the beads in alkaline $\mathrm{pH}$ could be explained by the ion exchange phenomenon between the calcium ion of ionotropically crosslinked DRG-alginate beads and the sodium ions present in phosphate buffer. The ion exchange takes place under influence of calcium sequestrates phosphate ions, which may result into disaggregation of DRG-alginate matrix structure leading to erosion and dissolution of swollen beads (Gaudio et al., 2005; Al-Kassas et al., 2007). It was found that beads prepared using high SA:DRG ratio in high concentration of cross-linking agent showed reduced swelling and faster erosion which may be due to lower amount of 
DRG that leads to the loss of viscosity of the gel structure of bead in the buffer and increase in the porosity of the bead matrix due to higher concentration of cross-linking agent.

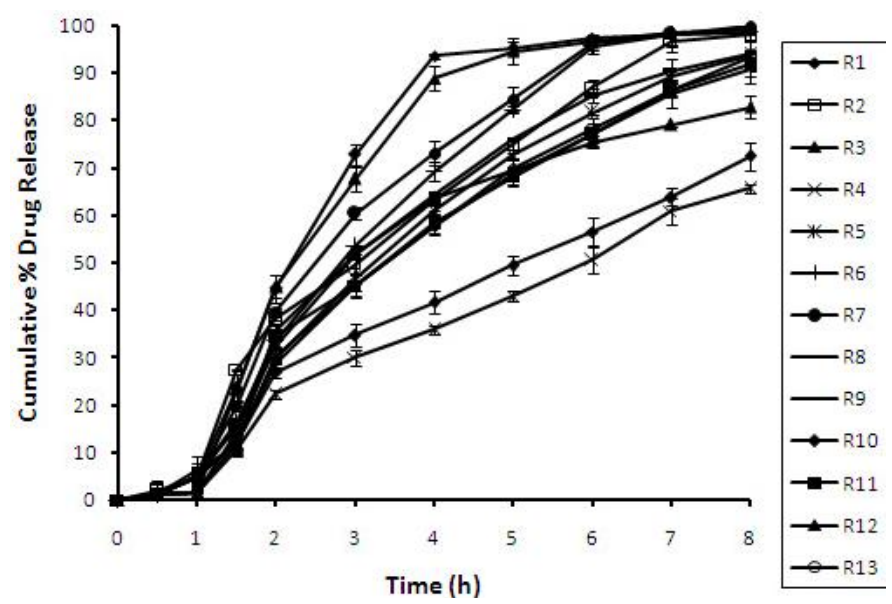

Fig. 5: In vitro drug release of DRG-alginate IPN beads.

\section{In vitro drug release and kinetics}

The DRG-alginate beads retarded the release of DS in acidic medium, due to poor solubility of DS as well as alginate at lower $\mathrm{pH}$. A trace amount of drug which might be adhered to the surface of the beads was released in acidic environment. The DRG-alginate beads showed prolonged drug released for $8 \mathrm{~h}$ in phosphate buffer, $\mathrm{pH}$ 6.8. Figure 6 shows the cumulative percentage of drug release of prepared thirteen runs. The release of drug was found to be retarded due to swelling of beads which leads to increased path length to travel drug into dissolution medium. The results obtained have been shown in Table 2. All formulations showed more than $85 \%$ drug release at the end of $8 \mathrm{~h}$ except R1 (72.4\%) and R4 (65.6\%).

The SA:DRG ratio in R1 and R4 was low whereas the concentration of the cross-linking agent used during their preparation was high. The high amount of DRG increases hydrophilicity leading to formation of viscous gel structure with water which may have blocked the pores on the surface of beads and sustained the release profile of drug. The gel strength of the beads increases with increase in the concentration of cross-linking agent which may also retard the drug release. As ratio of SA to DRG was decreased, drug release was found to be reduced while increase in the concentration of calcium chloride decreased the release of drug. It was found that at high SA:DRG ratio, increase in concentration of calcium chloride increases the release of DS. This opposite behavior of cross-linking agent may be due to reduced swelling which shortens the diffusion path of the drug and faster erosion of the bead matrix as observed in case of swelling study.

The curve fitting results of in vitro drug release kinetics (Table 6) data indicated that, release of DS from DRG: alginate IPN beads was found to be following Higuchi model $\left(\mathrm{R}^{2}=0.832\right.$ 0.994 ) over the period $8 \mathrm{~h}$. The value of release exponent (n) determined from in vitro DS release data of various DRG-alginate beads ranges from 0.539 - 0.832, indicating anomalous (nonfickian) diffusion mechanism of drug release. This demonstrates both, diffusion controlled and swelling controlled drug release from DRG-alginate IPN beads containing DS.

\section{CONCLUSION}

The present work is a successful attempt to prepare DRG-alginate IPN beads by ionotropic gelation method and their optimization using central composite design. The investigations have revealed that the attempt to increase the DEE of the beads reduced the release of drug from the matrix. The optimized beads containing DS showed a better drug encapsulation efficiency $(51.74 \pm 1.54 \%)$ and release of drug in $8 \mathrm{~h}(89.68 \pm 2.52 \%)$. The in vitro drug release from these beads followed a controlled release pattern (Higuchi kinetics) with anomalous (non-fickian) diffusion mechanism. The optimization of DRG-alginate IPN beads containing DS contributes towards formulation of DRG-alginate IPN beads with high encapsulation efficiency along with sustained and maximum release of drug in $8 \mathrm{~h}$. Besides, the excipients such as sodium alginate, DRG and calcium chloride used for the formulation of these beads were cheap and easily available. Delonix regia gum-alginate IPN beads could be a better alternative to the conventional alginate beads or the beads prepared by blending alginate with other natural polymers.

\section{ACKNOWLEDGMENT}

Authors are thankful to Yashoda Technical Campus, Faculty of Pharmacy, Satara for providing facilities to carry out the work.

\section{REFERENCES}

Alebiowu G, Adetogun GE. Properties of Delonix regia seed gum as a novel tablet binder. Acta Pol Pharm, 2009; 66(4):433-438.

Ancona DB, Aguirre JP, Ruelas AC, Guerrero LC. Microencapsulation of papain using carboxymethylated flamboyant (Delonix regia) seed gum. Innovative Food Sci Tech, 2011; 12 (1): 67-72.

Bhattacharya SS, Ghosh AK, Banarjee S, Chattopadhyay P, Ghosh A. $\mathrm{Al}^{3+}$ ion cross-linked interpenetrating polymeric network microbeads from tailored natural polysaccharides. Int J Biol Macromol, 2012; 51 (5): 1173-1184.

Bogtaj M, Smrdel P, Mrhar A. The influence of selected parameters on the size and shape of alginate beads prepared by ionotropic gelation. Sci Pharm, 2008; 76: 77-89.

Chowdary KPR, Mohapatra P, Murali Krishna MN. Evaluation of olibanum and its resin as rate controlling matrix for controlled release of diclofenac. Indian J Pharm Sci, 2009; 68:497-500.

Das MK, Senapati PC. Evaluation of furosemide-loaded alginate microspheres prepared by ionotropic external gelation technique. Acta Pol Pharm, 2007; 64(3):253-262.

El-Kamal, AH, Al-Gohary OMN, Hosny EA. Alginate diltiazam beads: optimization of formulation factors, in vitro and in vivo bioavailability. J Microencap, 2003; 20 (2): 211-225.

Gaudio PD, Colombo P, Colombo G, Russo P, Sonvico F. Mechanisms of formation and disintegration of alginate beads obtained by prilling. Int J Pharm, 2005; 302(1-2): 1-9.

Giri TK, Verma S, Alexander A, Ajazuddin BH, Tripathy M, Tripathi DK. Crosslinked biodegradable alginate hydrogel floating beads 
for stomach site specific controlled delivery of metronidazole. Farmacia, 2013; 61(3): 533-550.

Guerrero 1AC, Ruiz JCR, Campos MRS, Ancona DAB. Encapsulation of phaseolus lunatus protein hydrolysate with angiotensin-converting enzyme inhibitory activity. ISRN Biotechnology, 2013:1-6.

Hua S, Ma H, Li X, Yang H, Wang A. pH-sensitive sodium alginate/poly (vinyl alcohol) hydrogel beads prepared by combined $\mathrm{Ca}^{2+}$ crosslinking and freeze-thawing cycles for controlled release of diclofenac sodium. Int J Biol Macromol, 2010; 46: 517-523.

Hunter JS, Princeton NJ. Statistical design applied to product design. J Quality Tech, 1985;17(4): 210-221.

Iannuccelli V, Forni F, Vandelli MA, Bernabei MT. Effect of the loading method on the drug release from crosslinked carboxy methyl cellulose beads. J Control Release, 1993; 23:13-20.

Krishnaraj K, Chandrasekar MJN, Nanjan MJ, Muralidharan S, Manikandan D, Development of sustained release antipsychotic tablets using novel polysaccharide isolated from Delonix regia seeds and its pharmacokinetic studies. Saudi Pharm J, 2012; 20:239-248.

Mali KK, Dias RJ, Ghorpade VS, Havaldar VD. Sodium alginate microspheres containing multicomponent inclusion complex of domperidone. Lat Am J Pharm, 2010; 29(7): 1199-1207.

Migliaresi C, Chen J, Mangilio D, Bonani W, Qian Q. Modulating the release of drugs from alginate matrices with the addition of gelatin microbeads. J Bioact Compat Pol, 2014; 29 (3): 193-207.

Nayak AK, Das B, Maji R. Calcium alginate/gum arabic beads containing glibenclamide: development and in vitro characterization. Int $\mathbf{J}$ Biol Macromol, 2012; 51(5):1070-1078.

Nayak AK, Das B, Maji R. Gastroretentive drug delivery systems: a review. Asian J Pharm Clin Res, 2010; 3(1): 2-10.

Nayak AK, Pal D. Development of pH-sensitive tamarind seed polysaccharide-alginate composite beads for controlled diclofenac sodium delivery using response surface methodology. Int J Biol Macromol, 2011; 49(4):784-793.

Odeku OA, Okunlola A, Lamprecht A. Formulation and in vitro evaluation of natural gum-based microbeads for delivery of ibuprofen. Trop J Pharm Res, 2014; 13(10): 1577-1583.

Patel PN, Gobin AS, West JL, Patrick CW. Poly (ethylene glycol) hydrogel system supports preadipocyte viability, adhesion, and proliferation. Tissue Eng, 2005; 11(9-10):1498-1505.

Patil JS, Kamalapur MV, Marapur SC, Kadam DV. Ionotropic gelation and polyelectrolyte complexation: the novel techniques to design hydrogel particulate sustained, modulated drug delivery system: a review. Dig J Nanomater Bios, 2010; 5:241-243.
Racovita S, Vasilu M, Popa M, Luca C. Review polysaccharides based on micro and nanoparticles obtained by ionic gelation and their applications as drug delivery systems. Rev Roum Chim, 2009; 54: 709-718.

Salunkhe NH, Jadhav NR, Mali KK, Dias RJ, Ghorpade VS, Yadav AV. Mucoadhesive Microspheres based suppository containing granisetron hydrochloride for management of emesis in chemotherapy. J Phar Investi, 2014; 44: 253-263.

Sandra K, Silvana C, Pando S, Marangoni C, Igor P. Crystal structure of the Kunitz (STI)-type inhibitor from Delonix regia seeds. Biochem Biophys Res Com, 2003; 312: 1303-1308.

Satturwar PM, Mandaogade PM, Fulzele SV, Darwhekar GN, Joshi SB, Dorle AK. Synthesis and evaluation of rosin-based polymers as film coating materials. Drug Dev Ind Pharm, 2002; 28(2):381-387.

Silvana CP, Maria LO, Claudio AS, Luciana DC, Jose CN, Sergio M. Primary sequence determination of a kunitz inhibitor isolated from Delonix regia seeds. Phytochemistry, 2001; M57: 625-631.

Singh B, Chakkal SK, Ahuja N, Formulation and optimization of controlled release mucoadhesive tablets of atenolol using response surface methodology. AAPS PharmSciTech, 2006; 7(1): E19-E28.

Tommasina C, Pietro M, Carlotta M, Franco A. Polysaccharide hydrogels for modified release formulation. J Control Release, 2007; 111 $5-24$

Torres D, GarcianEncina G, Seijo B, VilanJato JL. Biopharmaceutical evaluation of microencapsulate ion exchange resins containing diclofenac. Eur J Pharm Biopharm, 1995; 41:127-131.

Yamanaka S, Yuguchi YH, Urakawa K, Kajiwara M, Shirakawa $\mathrm{K}$, Yam. Gelation of tamarind seed polysaccharide xyloglucan in the presence of ethanol. Food Hydrocolloid, 2000; 14: 125-128.

\section{How to cite this article:}

Remeth Jacky Dias, Vishwajeet Sampatrao Ghorpade, Vijay Daulatrao Havaldar, Kailas Krishnat Mali, Nitin Hindurao Salunkhe, Jyoti Harishchandra Shinde. Development and optimization of interpenetrating network beads of Delonix regia gum and sodium alginate using response surface methodology. J App Pharm Sci, 2015; 5 (05): 056-064. 